\title{
Intertextualidad con la narrativa clásica: Odiseo y Penélope en la última etapa del teatro de Vargas Llosa
}

\section{Intertextuality with Classical Narrative: Odysseus and Penelope in the Last Stage of Vargas Llosa's Theater}

\author{
Luis Landa \\ Pontificia Universidad Católica del Perú
}

\begin{abstract}
También en Cochabamba vi mi primera obra de teatro; no me refiero a las veladas y representaciones escolares, sino a un drama de gente mayor que mis abuelos y mi madre me llevaron a ver, desde un palco del Teatro Achá, en función nocturna. Mi único recuerdo de la obra es que, en un momento dado, ante la consternación de todo el mundo, un señor le daba una sonora cachetada a una señora.
\end{abstract}

\section{RESUIMEN}

El artículo propone una segmentación de la producción teatral de Mario Vargas Llosa a partir de tres etapas. De ellas, destaca la tercera y última, en la que se han publicado las obras Odiseo y Penélope (2007), Las mil noches y una noche (2010) y Los cuentos de la peste (2015). Es evidente que el autor trabaja estas tres obras dramáticas de manera intertextual con narraciones clásicas. De tal forma que la propuesta fundamental de Vargas Llosa en esta etapa es relacionar aspectos dramáticos con narrativos. El presente artículo revisa este punto a partir del análisis de la pieza Odiseo y Penélope con referencias a las otras dos como parte de una exploración del terreno donde convergen las técnicas narrativas de Vargas Llosa y su afición por el teatro.

\section{Palabras clave:}

Mario Vargas Llosa / Teatro / Intertextualidad / Narrativa / Literatura clásica

\section{ABSTRACT}

This paper proposes a three-stage-segmentation of Mario Vargas Llosa's theater. The third - and last - stage contains his remarkable published works Odysseus and Penelope (2007), The thousand nights and one night (2010) and Tales of the plague (2015). Evidently, the author has worked these dramatic plays intertextually with classical narratives. Thus, the fundamental proposal of Vargas Llosa in this stage consists on linking drama to narrative. This paper studies this factor based on the analysis of Odysseus and Penelope making reference to the other two works as part of an exploration in a land where the narrative techniques of Vargas Llosa and his fondness for theater converge.

\section{Keywords:}

Mario Vargas Llosa / Theater / Intertextuality / Narrative / Classical Literature 


\section{Origen dramático}

La huida del Inca (1952) es un referente constante cuando los estudios y análisis de las obras de Mario Vargas Llosa buscan sus orígenes como creador de ficciones. Si bien esta pieza teatral se escribió en el ámbito particular del colegio, resulta un innegable debut en la dramaturgia, línea de la creación que, en reiteradas oportunidades, el mismo Vargas Llosa ha reconocido como una de sus pasiones ${ }^{1}$. Aunque esta obra no ha sobrevivido más allá de su efímero montaje en el Teatro Variedades y de los recuerdos de su gestación durante su estadía en el colegio San Miguel en Piura, en definitiva, se trata de un lance oficial en el teatro y, por lo tanto, en la creación literaria del escritor.

\section{Tres periodos de producción teatral}

Mario Vargas Llosa ha publicado - hasta hoy - nueve piezas teatrales, con lo que demuestra una sólida inclinación por el género que, sin embargo, no le ha reputado tanto como sus obras narrativas. Aunque todas ellas llevan el sello de la poética de su autor -en detalles como la superposición de planos, los datos escondidos, las diferentes líneas de acción que se presentan con sus respectivos vasos comunicantes, entre otros recursoses evidente la tendencia en la evolución de su dramaturgia hasta en tres etapas. La primera -donde se encuentran las obras de iniciación La señorita de Tacna (1981), Kathie y el hipopótamo
(1983), La Chunga (1986) - se trata de una exploración de su universo dramático bastante paralelo a su universo narrativo en cuanto a técnicas, demonios y temas. Es una suerte de conversación entre la narrativa y la representación teatral que se gesta durante la década de 1980. La segunda etapa se encuentra compuesta por el siguiente impulso de obras publicadas durante las próximas décadas y que abarca desde El loco de los balcones (1993), Ojos bonitos, cuadros feos (1996), y que se prolongaría (con un "enroque" con la siguiente etapa) hasta Al pie del Támesis (2008), periodo en el que la exploración temática se extiende más allá de la profundización en los demonios recurrentes, motivo por el cual, incluso, los personajes no evocan necesariamente otras obras narrativas como en algunas de las piezas de la primera etapa, donde aparecen Santiago Zavala y los inconquistables, por ejemplo. La tercera se encuentra compuesta por Odiseo y Penélope (2007), Las mil noches y una noche (2010) y Los cuentos de la peste (2015). En esta última propuesta dramática, resulta evidente que lo que destaca es un cambio en relación con las motivaciones anteriores, a pesar de los recurrentes vínculos que entrelazan su poética; porque la intertextualidad se convierte en la fuente de inspiración de esta última producción a la que Vargas Llosa se ha abocado no solo en su calidad de creador, sino en su capacidad de performance. El carácter de esta última tendencia en la dramaturgia de Mario Vargas Llosa es lo que concita las reflexiones de este artículo. En él se analizará Odiseo y Penélope, que es la pieza que, fundamentalmente, abre esta tercera etapa y se mostrarán algunas referencias breves a las otras obras - Las mil noches y una noche y Los cuentos de la peste- como refuerzo de los argumentos acerca del carácter que vincula el teatro con la narrativa y los principios intratextuales en la obra de Vargas Llosa.

\section{La última etapa de la intertextualidad con el acervo narrativo clásico universal}

Aunque las piezas anteriores - hasta cierto punto- han mantenido el carácter realista que dispone sus pies con firmeza sobre el espacio peruano, con las obras de esta tercera etapa, Vargas Llosa logra una fusión bastante sugerente. Mantiene algunos detalles de su perspectiva peruana, sobre todo, evidentes en el lenguaje (sustrato fundamental del teatro); $y$, por primera vez, añade el lado universal que se puede reconocer en la impronta que han dejado los clásicos con los que conversa, de los que surgen las piezas teatrales de este último periodo. Se podría, además, observar un trabajo constante entre un ámbito individual (hasta el fuero interno) de los personajes y lo colectivo que implica el reconocimiento que las historias convocadas motivan.

En este sentido, la intertextualidad literaria constituye la base del último periodo dramático que experimenta Vargas Llosa. Las sendas obras evocadas por cada una de las piezas teatrales que ha escrito corresponden con tres grandes relatos de la literatura universal. El vínculo entre narrativa y teatro, que espontáneamente

1 Uno entre los muchos momentos en los que Vargas Llosa refiere su pasión por el teatro se encuentra en este fragmento del discurso que pronunció en la ceremonia de la entrega del premio Nobel en Suecia en 2010: "El teatro fue mi primer amor, desde que, adolescente, vi en el Teatro Segura, de Lima, La muerte de un viajante, de Arthur Miller, espectáculo que me dejó traspasado de emoción y me precipitó a escribir un drama con incas. Si en la Lima de los cincuenta hubiera habido un movimiento teatral habría sido dramaturgo antes que novelista" (2015b, p. 117). Y sobre La huida del Inca: "No me fue nada mal con mi primera obra de teatro. Ganó el segundo premio de un concurso de obras de teatro infantil convocado por el Ministerio de Educación y tuve la alegría de verla sobre el escenario del Teatro Variedades, de Piura, en junio de 1952, dirigida por mí mismo. [...] Estaba todavía en el colegio, pero, con mis dieciséis años, ya me sentía un escritor” (2007, p. 121). 
encuentra Vargas Llosa (2007) en sus creaciones, lo conducen a afirmar lo siguiente:

Siempre consideré el teatro el reverso de la novela, es decir, otra manera de contar historias, más íntima e inmediata, algo que establecía entre ambos géneros una consanguinidad irrenunciable, y desde entonces pensé que lo más difícil de lograr -el mayor triunfo de un novelista 0 un dramaturgo - era contar una historia bien contada, es decir, de manera tan contagiosa que no pareciera ficción, sino la vida atrapada y expuesta en un libro 0 sobre las tablas. (p. 126)

Las tres obras clásicas, La Odisea, Las mily una noches, el Decamerón, vinculadas a las piezas dramáticas, permiten observar, evidentemente, una relación intertextual entre los géneros narrativo y teatral que permiten al novelista explorar vínculos que se intersecan en ambos, de tal manera que este último periodo de su producción teatral se separa, así, de las etapas anteriores. Estas se concentran en desarrollar los recursos teatrales y exploran el vínculo entre la ficción literaria y la "vida misma". Estas primeras dos etapas no muestran una intención tan evidente de destacar relaciones con aspectos del género narrativo, como, claramente, sí se exponen en esta última y tercera etapa.

Nos encontramos ante un proyecto sobre la base de una deliberada elección de clásicos del ámbito mítico y, además, popular; pero, sobre todo, Vargas Llosa ha escogido narraciones, donde la carga del relato dentro de ellas es especial, porque cada uno de sus protagonistas cumple el rol de contadores de historias, pues ellos mismos ejecutan relatos con la conciencia de hacerlo, a la vez que la obra narrativa se va desarrollando. En primer lugar, se encuentra Odiseo, quien, en el poema homérico, es el protagonista que asume la narración de sus peripecias en la corte del rey Alcínoo. En segundo lugar, Sherezade narra noche a noche, ante el rey Schariar, las historias que se entretejen para mantener el suspenso que le salvará la vida en Las mil y una noches. Finalmente, cada uno de Ios diez jóvenes que protagonizan el Decamerón de Boccaccio narra cada una de las historias que desarrollan la obra mientras la peste los cerca en Florencia. Todos estos protagonistas tienen el carácter 0 emprenden el rol de ser narradores en tres de las más conocidas obras narrativas que, desde la perspectiva de Vargas Llosa, también resultan "dramatizables"2.

Trasladar parte del contenido de estas tres historias del género narrativo al dramático implica una inevitable transformación del sustrato clásico. Un proceso de condensación resulta la primera evidencia de la metamorfosis natural que sufren las tramas con una reestructuración como la que experimentan. Por ello, no se trata de versiones simplemente adaptadas o recortadas, sino, obviamente, de un trabajo de construcción dramática que, sobre la base del relato original, ejecute las disposiciones necesarias que la creatividad del autor permita sostener incluso en la puesta en escena. Por ello, a diferencia de Pierre Menard, Vargas Llosa no crea otra vez los clásicos en nuestra época, o los recorta, sino que, de ellos, construye los dramas autónomos que conversan con elementos de sus reconocidas fuentes. En este sentido, hay un espacio de personalización de la historia que va más allá de la libertad que un director teatral tiene al momento de poner un clásico en escena.

¿En qué consiste la creatividad de Vargas Llosa sobre estos clásicos? En primer lugar, el autor es consciente del punto desde el que parte su obra: la aparente actualidad y el realismo. Aunque de las tres piezas teatrales, Odiseo y Penélope sea la que más respeta la historia original, partir de la metaficción $^{3}$ que construyen los personajes no solo la aleja de la Odisea, sino que le imprime un sello característico de Vargas Llosa: ese constante juego para el lector/espectador basado en la verdad de las mentiras. De la misma manera que las demás obras elegidas como base para esta etapa del teatro de Vargas Llosa, la Odisea posee un relato dentro del mismo cantar: la intervención de Odiseo en la corte del rey de los feacios, donde narra sobre sus propios viajes y aventuras hasta que se descubre su identidad (durante Ios cantos IX y XII). Esto puede interpretarse como una referencia metaficcional dentro de la misma epopeya. El lector/espectador, quien conoce los clásicos, asume la metaficción y añade su cuota al apreciar la manera en que la simbología de las obras teatrales se enriquece a partir de la intertextualidad. Probablemente, por ello, el trabajo con los títulos sea un referente de base para anunciar la autonomía de la pieza teatral frente al clásico narrativo. No se trata de la Odisea, sino de Odiseo y Penélope; no se trata de Las mil y una noches, sino de Las mil noches y una noche (aunque se objete que esta

2 Al respecto, por ejemplo, sobre el Decamerón, Vargas Llosa (2015a) opina acerca de aspectos que se reiteran en las otras dos obras. "Desde la primera vez que leí el Decamerón, en mi juventud, pensé que la situación inicial que presenta el libro, antes de que comiencen los cuentos, es esencialmente teatral. [...] La circunstancia que sirve de marco a los cuentos del Decamerón no puede expresar mejor la naturaleza de lo teatral: representar en un escenario algo que, mientras dura, es vida que reemplaza a la vida real, a la vez que la refleja con sus carencias y añadida de lo que nuestras necesidades y urgencias quisieran que tuviera para colmarnos y hacernos gozar de ella a plenitud" (pp. 13-14).

3 Aplico el concepto "metaficción" siguiendo la analogía con el término lingüístico "metalenguaje" (lenguaje que se refiere al lenguaje); es decir, la metaficción se asume como una referencia directa desde la ficción a la ficción misma; de tal manera que un relato dentro del relato ya se presenta como una relación metaficcional, así como el deliberado recuento de los hechos que han sido presentados en la misma obra. Con mayor profundidad, sobre otras aplicaciones del término y su variante "metateatro", ver Rivera-Rodas (1992). 
pueda ser una traducción plausible del título original); no se trata del Decamerón, sino de Los cuentos de la peste. Asimismo, como ya se ha referido, la conciencia de la literatura, de la metaficción, de la superposición de líneas dramáticas (por no llamarlas pequeñas acciones dramáticas) hacen de las piezas de Vargas Llosa, obras comunes a nuestro tiempo, modernas, que reflejan aspectos de su poética y que, además de generar una evidente nueva etapa en su dramaturgia, amplían su largo currículo creativo.

Cabe añadir que esta última aventura expresa una adenda en el proceso de creación: Vargas Llosa ha ejecutado no solo el lado literario del teatro, sino también el lado del espectáculo, al haber participado como actor en cada una de las tres piezas. Así, creación e interpretación cierran un círculo teatral.

Jamás hubiera escrito Odiseo y Penélope sin haber vivido antes la experiencia, formidable para mí, de subirme a un escenario a contar desde allí, e interpretar por breves momentos, junto a una actriz profesional, La verdad de las mentiras. [...] Como escritor, he dedicado buena parte de mi vida a escribir historias que fingieran ser la vida verdadera, cuando eran sólo hechizo, espejismo, vida hecha palabras. Pero sólo ahora tenía la impresión de estar sumergido en cuerpo y alma en la maravillosa vida de la ficción que tomaba forma en aquellos escenarios donde Aitana y yo contábamos leíamos y representábamos las fantasías concebidas por un puñado de los mejores fabuladores de nuestro tiempo. (Vargas Llosa, 2007, p. 146)
La primera obra de este ciclo dramático es Odiseo y Penélope, que surge de un proyecto anterior titulado La verdad de las mentiras (como su libro de ensayos publicado en 1990) en el que Vargas Llosa leía e interpretaba, junto a la actriz Aitana Sánchez-Gijón, pasajes de una selección de obras literarias. Tras el feliz encuentro de ambos con el director Joan Ollé, en esta adaptación de textos llevada al espectáculo, cuajó el segundo proyecto que, finalmente, constituye la pieza teatral compuesta por Vargas Llosa. En su versión, el autor propone como presente del drama el momento cuando Odiseo ya mató a los pretendientes. Es decir, no concuerda con el poema homérico, como tampoco sucede necesariamente con las piezas siguientes y sus referentes narrativos. La situación presenta a Odiseo y Penélope realizando un ejercicio de expiación simultáneo, para el que combinan sus perspectivas del pasado y reflexionan sobre los hechos acaecidos que los han conducido al contexto propicio en el que se muestran al público. Cabe destacar que solo en esta pieza teatral se amplía la intertextualidad con la lírica y lo griego evocado desde el presente, es decir, desde nuestra modernidad, al inicio del libro publicado; ya que en la edición presentada se incluye la inserción del poema Ítaca de Constantino Petrus Cavafis 5 .

En la obra teatral se incorpora un narrador que inicia el discurso y, apenas surge la acción dramática, este se transforma en actor: "El narrador convertido en Odiseo, toma su puesto junto a Penélope" (Vargas Llosa, 2007, p. 18). Con este recurso se pretende resaltar el vínculo con lo narrado, a partir de una aproximación al público. Como una especie de corifeo griego moderno, este personaje narra para el público, al inicio de la representación, en una aparente introducción. A diferencia de la composición homérica, el punto donde comienza la pieza teatral implica una prolongación de un momento íntimo: la conversación que Odiseo mantiene con Penélope luego de la matanza de los pretendientes. Esta perspectiva establece una diferencia más en el tratamiento del tema, pues en la pieza teatral, el drama amoroso adquiere una presencia constante que supera al componente de aventura y que, incluso, se resalta en detalle en algunos puntos, como cuando Odiseo confiesa sentirse celoso e intercambia con Penélope sus emociones ocultas en "exordios" que los alejan del relato y que nos muestran a ambos personajes como una pareja actual enamorada, discutiendo sus asuntos personales con un tono familiar muy alejado del solemne discurso de la epopeya.

Penélope. - ¿Y ese tono? ¿Y esas palabras vulgares? ¿Y ese brillo beligerante en tus ojos? Se diría que estás celoso, ODISEO.

OdISE0.- Estoy celoso.

Penélope.- ¿Si me hubieras encontrado casada me habrías matado a mí también, con tu espada sanguinaria?

Odiseo. - No con mi espada. A ti con mis manos. A tu marido le hubiera cortado las orejas, la lengua y la nariz. Y, también, por supuesto, muy despacio, la verga y los testículos, y se los hubiera dado de comer a los buitres. Luego, en vez de ocupar el trono, me hubiera marchado para siempre de esta isla. A seguir corriendo

4 A esto se podría añadir un punto de su reflexión en la introducción de Cuentos de la peste (2015a) "Los actores son esos "otros" que todos quisiéramos ser, esos que, sin dejar de ser lo que son, son también muchos, según los papeles que encarnan en cada representación. Los actores lo son profesionalmente. Los demás, el común de los mortales, lo somos sin exhibirlo, cuando "actuamos" guardando las formas y las convenciones sociales, cuando superponemos a nuestro yo auténtico un yo social, o cuando, en el secreto de nuestra intimidad, nos abandonamos a la fantasía de ser otros, de hacer lo que nunca hicimos ni haremos en la realidad." (pp. 34-35).

5 Poeta por el que Vargas Llosa ha demostrado una abierta preferencia al escogerlo para la publicación de su proyecto en tándem con Fernando de Szyszlo: el poema El Alejandrino (Bogotá: Arte Dos Gráfico, 2014). 
mundo, como el mendigo en que me convirtió Palas Atenea. Hubiera tratado de ganarme la vida contando mis aventuras.

Penélope.- No me hubieras matado. Me hubieras perdonado, como te he perdonado yo todas las mujeres que has tenido en tus brazos los veinte años que estuvimos separados. Circe, Calipso, Nausica. Pero, hubo otras, ¿verdad?

OdISEO.- Este tema me turba. Te lo contaré todo, poco a poco. Pero, después. Ahora volvamos a la historia. Recorrer mi propio reino, como mendigo, ha sido triste e instructivo, Penélope. (Vargas Llosa, 2007, pp. 96-97).

Así, lo que se refiere en el drama se expresa en una atmósfera íntima que la epopeya no necesita relatar de esta manera coloquial, con demasiado detalle, y que solamente se expresa en el diálogo del reencuentro de los esposos hacia el final del canto XXIII, en un tono que mantiene la solemnidad. En la pieza teatral, Odiseo cuenta también los hechos acaecidos a su esposa, pero no se trata de un resumen demasiado sucinto como en el cantar. Este espacio de interacción conyugal del relato homérico se extiende y desde él parte el recuento de la odisea, de la aventura. Asimismo, Penélope interviene en el relato como si lo conociera (¿o como si lo hubiera leído?) de antemano. De esta manera, como Odiseo, el narrador -Penélope asume el rol de los personajes narrados. Por ejemplo, tuerce la voz para decir lo que pronunciará Polifemo en un momento determinado. Ella también asume la conducción del relato y, cuando, por ejemplo, refiere los hechos acerca de la aventura con Circe, Penélope le cuenta la acción al mismo Odiseo, quien se convierte en receptor explícito a través del vocativo.

Penélope.— Los invitó a pasar. Todos entraron, menos Euríloco, que, desconfiado, o alertado por algún dios, se quedó fuera, espiando.
Lo vio todo. ¡Ah, qué horrible, Odiseo! Circe hizo sentar a los hombres en unas sillas y sillones que refulgían de piedras preciosas. Les preparó de comer, mezclando queso, harina, miel, vino de Pramnio y unos polvos mágicos, que los incautos paladearon gozosos. Mientras comían, la hechicera los tocaba con su varita, como jugando.

¡Euríloco lo veía y no lo creía, Odiseo! (Vargas Llosa, 2007, pp. 38-39)

En cuanto al trabajo con el discurso, es evidente la diferencia de los lenguajes que se aplican para cada género. Es interesante, sin embargo, apreciar la diferencia entre la expresión del discurso de la epopeya y la del drama cuando se refieren los mismos hechos. E discurso en el drama de Vargas Llosa presenta mayores detalles debido a la atmósfera y perspectiva subjetiva que se logra con la aplicación de adjetivos y pormenores en las descripciones. Si bien la epopeya presenta también detalles, no siempre se ejecuta esto desde una voz próxima, como en el drama, sino más bien desde una perspectiva "alejada", más "objetiva" hasta cierto punto. Y, por supuesto, esta voz narrativa no se encuentra exenta de emociones (incluso con intervenciones personales, como la compasión o el dolor).

La estructura usada por Vargas Llosa -no solo en esta, sino en las otras dos piezas de la etapa - se desarrolla a partir de una división en "cuadros", titulados según el momento recontado, por ejemplo, el cuadro $V$ se titula: "El canto de las sirenas". Es así como la acción dramática engendrada por el relato hace que los personajes prolonguen la pieza. En este sentido, se apela a un recurso de base ya utilizado en Kathie y el hipopótamo: Ios personajes imaginan y recrean la historia.

PenÉlOPE.- ¿Quieres que juguemos a inventar el pasado, Odiseo?

ODISEO.- No a inventarlo. A hacerIo, a vivirlo de verdad, otra vez, con la fantasía y la memoria, pero, ahora, juntos. El pasado es maleable como la arcilla, depende de nosotros tanto como el futuro, Penélope. (Vargas Llosa, 2007, p. 25)

Asimismo, en Las mil noches y una noche Vargas Llosa apela a un recurso ya usado desde La tía Julia y el escribidor. incorporar elementos de la realidad como los nombres para tensar el límite entre la ficción y la realidad; de tal manera que los personajes de esta obra se llaman Mario y Aitana y hacen referencia a su proyecto anterior con Odiseo y Penélope. En líneas generales, en estas tres piezas teatrales, se aprecia una superposición de planos entre lo que el personaje se imagina y la concreción de lo imaginado, que es una característica frecuente en el teatro de Mario Vargas Llosa, evidente desde la compleja realidad que se representa en La señorita de Tacna. Con esta superposición de planos se obtiene un efecto fundamental en la representación que el lector/espectador activo debe captar: se "actualizan" dos dimensiones, el presente representado y lo imaginado 0 el pasado. Se multiplican los "espacios" representados, como proliferan las líneas narrativas en las novelas del autor, e interactúan estos espacios representados de manera similar como en los diálogos telescópicos, las mudas o los vasos comunicantes.

En la aplicación de este efecto llama la atención, además, el recurso dramático de la pausa para cambiar de focalización. Por ejemplo, en el cuadro IV, titulado "La morada de las sombras", Odiseo y Penélope cuentan la aventura en el Hades y, mientras Odiseo actúa (y actualiza el pasado), al conversar con Tiresias (Penélope convertida en el viejo adivino) realiza una pausa (marcada en el texto) de manera que, luego de ella, se pregunta: "¿Eres tú, Anticlea? Madre, madre mía, ¿tú también en el Hades?" (Vargas Llosa, 2007, p. 49); en ese momento, Tiresias ya no está más frente a él, sino, efectivamente, Anticlea. Esto se complejiza aún más cuando en la siguiente pausa se aprecia una superposición de planos, 
pues de conversar con Anticlea (y actualizar así el pasado), Odiseo se refiere en el presente a cómo intentó en vano abrazarla tres veces; luego se hace una nueva pausa y los lectores/ espectadores se encuentran de nuevo con un Odiseo, que actualiza el pasado, esta vez en procura del reconocimiento de la sombra augusta de Tiro. Las pausas se aprovechan así para pasar del Odiseo "narrador" del presente al Odiseo "actor", que ejecuta acciones del pasado y, de esa manera, lo actualiza, Io representa. ¿Estaría aplicando Vargas Llosa esta pausa que permite el cambio de foco como un recurso que aprovecha constantemente en sus más complejas narraciones bajo los discursos directos e indirectos?

Excepto Los cuentos de la peste, las obras están pensadas para la representación de dos actores que no solo asumen sus propios roles, sino también las voces de otros y, obviamente, con ello, identidades y roles ajenos. Esto no es nuevo en teatro, por supuesto, pero sí constituye un recurso que determina la modernidad de la pieza. Así, Odiseo asume el rol y la voz de Aquiles, siendo consciente de este acto. Lo mismo sucede cuando usurpa el rol de Euríloco, entre otros más. Por su parte, Penélope realiza lo mismo cuando asume la voz y el rol no solo de personajes femeninos, como Circe, por ejemplo ${ }^{6}$.

De esta manera es como se intercalan los discursos: la narración de Odiseo y de Penélope, los diálogos del pasado actualizado, los comentarios de Penélope, las voces en off de los dioses, etcétera. Probablemente como la experimentación radical con los diálogos telescópicos y algunos discursos en Conversación en La Catedral, se podría prestar atención, asimismo, a la dirección que adoptan los textos expresados por un personaje en un determinado momento. Por ejemplo, cuando Odiseo relata su paso por la isla Ogigia, ¿le habla o confiesa lo ocurrido a Calipso o a Penélope, respectivamente?

Penélope. - La amaste, entonces.

Odiseo. - No la amé, solamente la deseé. Y le hice el amor, sí. Pero tampoco a ella, igual que a Circe y a las otras mujeres que los dioses pusieron en mis brazos en estos años de ausencia, pude amarla. El recuerdo de Penélope se interponía siempre entre ellas y yo. Y me impedía amar a las mujeres que deseaba. Lo siento, Calipso. Te he dicho la verdad.

Calipso.- No lo sientas. Pronto olvidarás a tu esposa Penélope, como ella debe de haberte ya olvidado. (Vargas Llosa, 2007, pp. 77-78)

Al igual que en la novela, la agilidad, gracias a la complicidad del lector/ espectador, es el resultado tanto de esta técnica como cuando el cambio de dirección se marca también a veces en el texto con comillas:

Penélope. - ¿Los dioses se aburren, quieres decir?

Odiseo.- A lo mejor, sí. 0 no. Gracias a la muerte, la vida es goce, aventura, intensidad, ilusión. Para los inmortales nunca lo es. [...] ¿Qué clase de anhelos, de pasiones, de excitación, de inquietud, tendríamos, si el riesgo de entrar en el reino de las sombras, de volvernos una sombra, no nos acechara a cada paso?
Lo siento, ninfa. No, no, la perspectiva de ser inmortal, gracias a la ambrosía y a estas vestiduras que me has çdado, no me ilusiona. Me horroriza.

CaLIPSO.- No necesitas decírmelo, Odiseo. (Vargas Llosa, 2007, p. 80)

\section{Desarrollo de la última etapa teatral}

En la segunda pieza teatral de esta tercera etapa, Las mil noches y una noche, separada de la anterior, Odiseo y Penélope, solo por la última obra de la segunda etapa de expansión temática, Al pie del Támesis, se sigue el mismo principio dual básico: Odiseo-Penélope // Sahrigar-Sherezada, que, luego, quizá porque esta última etapa comienza a complejizarse Ientamente, aumentará en Los cuentos de la peste. A diferencia de la primera obra de esta etapa, donde el protagonista masculino, Odiseo, era el narrador principal, en esta, la protagonista femenina, Sherezada, es la que conduce el hilo narrativo. $Y$, con más énfasis que en la obra anterior, en Las mil noches y una noche, los personajes - como si siguieran el principio del recurso literario de las cajas chinas - encarnan a otros personajes y se proyectan en ellos. Por ejemplo: Mario-Sahrigar-príncipe Camar Asamán o Aitana-Sherezada-princesa Budur. Así, paralelamente, se incorporan 0 entretejen las historias y las realidades representadas en una versión análoga al relato original. Así como las historias se entrecruzan o se derivan unas de otras en la obra narrativa original, Las mil y una noches, así también los personajes de esta pieza teatral encarnan, como narradores y bajo el rol de otros

6 Una reflexión cercana a esta multiplicidad de actuaciones podría encontrarse en el prólogo a Los cuentos de la peste, donde Vargas Llosa (2015a) ensaya una explicación acerca del origen de este recurso y de la conciencia de los personajes de su ejecución deliberada: "La vida real se va diluyendo en el curso de la obra hasta desvanecerse del todo en el laberinto de invenciones que cuentan y representan los cinco personajes, proceso en el que ellos mismos van desapareciendo y reapareciendo mientras sus vidas reales - que nunca conocemos a cabalidad - van siendo sustituidas por las vidas fantaseadas que relatan y encarnan de manera sucesiva. Ésta no es una operación fantástica sino de realismo fantástico -son cosas distintas-, pues es lo que hacen los actores cuando suben a un escenario a interpretar una obra y lo que hacemos todos los mortales cuando nos figuramos vivir aventuras o situaciones distintas a las que configuran nuestra existencia." (p. 30). 
personajes, una enredada y compleja red de superposiciones de realidades y de planos, cuestión dilecta también en la narrativa para Vargas Llosa.

También aquí se aplican voces en offy, asimismo, se aprecia la incorporación de música como leit motiv. Este es un recurso igualmente utilizado en Cuentos de la peste, porque, además, ambas obras mantienen la estructura esencial clara y deliberadamente de una serie de cuentos narrados por alguien en una similar modalidad que sería una variante a la que se propone en Odiseo y Penélope, donde todos los relatos proceden de las aventuras del protagonista.

A diferencia de las otras dos obras de esta última etapa, en Cuentos de la peste Vargas Llosa inserta personajes que no existen en el texto original. Esto muestra una apertura lenta hacia un proyecto mayor. Se abandona la dualidad que caracterizaba a las obras anteriores. Y, con Cuentos de la peste incluso se llega a presentar un personaje como Aminta, que parcialmente existe en la imaginación del duque Ugolino. En esta tercera pieza del ciclo los roles se exacerban desde el comienzo en el capítulo/escena I: "El hombre veneno y el fanático", donde en una suerte de mascarada, los personajes se presentan como los que "no son" o como lo que podrían encarnar. Y si los roles se multiplican después, lo mismo sucede también con los planos representados 0 simbolizados 0 aludidos.

Resulta interesante, además, observar la manera como Vargas Llosa continúa la experimentación con la metaficción. Como Odiseo, en Odiseo y Penélope, que en un determinado momento cuenta sus aventuras, Boccaccio se ha convertido en personaje en Cuentos de la peste, que pretende escribir un texto como el Decamerón apenas acabe el cerco impuesto sobre Florencia. Con ello, se apela al lector atento para que confirme una vez más el efecto metaficcional que existe espontáneamente en la Odisea, cuando el protagonista cuenta la historia de lo que le ha sucedido, mientras que aquí se trata de una inserción del autor del Decameron, como personaje, de absoluta responsabilidad creativa por parte de Vargas Llosa.

Y, tal como sucede en Odiseo y Penélope, en Cuentos de la peste se actualiza el pasado a través del recuerdo. Por ejemplo, se regresa al momento en que los personajes se encuentran en Santa María Novella, donde todo comenzó para ellos. Quizá podría entenderse esta actualización del pasado en función de la evocación del dato escondido y la relativización de lecturas de un hecho, tal como se aplicó en La Chunga, cuando se revela a través justamente de la actualización del pasado las especulaciones sobre el suceso de una noche. En el caso de la obra de 1986, resalta la versión de Josefino sobre el violento encuentro entre la protagonista y él durante la noche en que este llega con Meche al bar de la Chunga. De manera similar, se apela al dato escondido hipérbato en el caso de Cuentos de la peste, cuando se evita la explicación concreta del odio de Aminta por Ugolino, hasta que se revelan los sucesos ocurridos durante la segunda noche del casamiento de la pareja, cuando Aminta es ultrajada por el monstruo Barbanto con el consentimiento del duque. Ambas situaciones se han mantenido ocultas al lector como un dato escondido que se revela en su mayor parte avanzada la trama.

\section{En la mitad de la travesía}

Las tres obras mantienen un tratamiento común del tema sexual que permanece como fundamento de la acción. Tanto las aventuras relatadas sobre las tablas con Circe, Calipso, Nausica, con la situación de Sherezada y Sahrigar, y con los enredos que se refieren en Cuentos de la peste, como las narraciones originales, de los que parten los dramas, expresan un tratamiento actual de la eterna e inago- table fuente literaria del sexo, el amor y sus derivados que, como buenos clásicos, emanan de la ontología del ser humano. Este es un eje transversal de la última etapa. Así también lo es la constate reflexión sobre contar/narrar y vivir la experiencia desarrollada desde diferentes perspectivas; es decir, una búsqueda del balance entre lo que se ha vivido con la experiencia y la capacidad de verbalizar esto a través de la expresión.

ODISE0.- Y hablé, hablé, no sé cuántas horas y días, en un palacio que a cada rato se llenaba de más y más gente. Escuchaban absortos. Reían, lloraban, se asustaban, se alegraban. Les conté de los lotófagos, de los cíclopes, de Circe, del Hades, de las sirenas, de Escila y Caribdis, de las vacas del sol y de mis siete años en la isla Ogigia, con la ninfa Calipso.

Sigue, sigue, aedo.

¿Qué más? ¿Qué pasó después?

[...]

Curioso, muy extraño, oír contar algo que yo había vivido. Los hechos eran exactos, pero las palabras, la música y el acento del aedo los distanciaba e irrealizaban. Todo aquello me parecía pura imaginación, pese a haberlo vivido. (Vargas Llosa, 2007, pp. 89-90)

Aunque no lo son, si las obras que componen esta última etapa de la dramaturgia de Vargas Llosa se reconocieran bajo la premisa del teatro de tesis, el argumento de base sería: la literatura (el teatro, la narrativa) nos aleja de la realidad y nos hace vivir otras vidas. Pareciera que este argumento se erige como el leit motiv de fondo en cada una de las piezas. El final de Odiseo y Penélope tiene ecos de Kathie y el hipopótamo en cuanto ya no se sabe si los hechos son referidos exactamente como los han vivido los protagonistas o si la fantasía los concreta (y deforma). De la misma manera, en Las mily una noches, suce- 
de algo similar cuando los personajes Mario y Aitana reflexionan sobre el poder que juntos convocan al contar e imaginar las historias. Tanto así sucede con el duque Ugolino, quien, más aun que sus compañeros de escenario, es consciente del poder de sugestión que logra con Aminta y las historias que han logrado transformar la realidad que lo circunda. Ficción y realidad se superponen, y el lector/espectador lo asume espontáneamente.

Desde el inicio de su carrera, una de las tesis más recurrentes del autor es que la literatura nos permite vivir otras vidas y nos aleja de la posible simpleza de la existencia y de la barbarie. Esta última etapa de su producción teatral que comienza con Odiseo y Penélope enfatiza explícitamente esta idea a través de sus protagonistas narradores y el conflicto central que los rodea. ¿Seguirá prevaleciendo esta idea en sus futuras obras dramáticas? En todo caso, se trata de un demonio que ha atravesado sus obras y que difícilmente quedará exorcizado con la adición de algunas piezas más a la lista.

\section{Bibliografía}

Forgues, R. (ed.). (2001). Mario Vargas Llosa, escritor, ensayista, ciudadano y político. Lima: Minerva.

Rivera-RodAs, 0. (1992). El metateatro y la dramática de Vargas Llosa. Amsterdam, PA: John Benjamins Publishing Company.

Vargas LlosA, M. (1969). Conversación en La Catedral. Barcelona: Seix Barral.

VARgas LloSA, M. (1981). La señorita de Tacna. Barcelona: Seix Barral.

Vargas LlosA, M. (1983). Kathie y el hipopótamo. Barcelona: Seix Barral.

Vargas Llosa, M. (1986). La Chunga. Barcelona: Seix Barral.

VARGAS LLOSA, M. (1993). El loco de los balcones. Barcelona: Seix Barral.

Vargas Llosa, M. (1996). Ojos bonitos, cuadros feos. Lima: Peisa.

Vargas Llosa, M. (2007). Odiseo y Penélope. Barcelona: Galaxia Gutemberg.

Vargas Llosa, M. (2008). Al pie del Támesis. Lima: Alfaguara.

VARgas Llosa, M. (2010). Las mil noches y una noche. Lima: Alfaguara.

Vargas LlosA, M. (2015a). Los cuentos de la peste. Lima: Alfaguara.

Vargas LloSA, M. (2015b). Elogio de la educación. Lima: Taurus. 